Boise State University

ScholarWorks

Physics Faculty Publications and Presentations

Department of Physics

$5-7-2014$

\title{
Defect Induced Ferromagnetism in Undoped ZnO Nanoparticles
}

\author{
K. Rainey \\ Boise State University \\ J. Chess \\ Boise State University \\ J. Eixenberger \\ Boise State University \\ D. A. Tenne \\ Boise State University \\ C. B. Hanna \\ Boise State University
}

See next page for additional authors

\section{Publication Information}

Rainey, K.; Chess, J.; Eixenberger, J.; Tenne, D. A.; Hanna, C. B.; and Punnoose, A.. (2014). "Defect Induced Ferromagnetism in Undoped ZnO Nanoparticles". Journal of Applied Physics, 115(17), $17 \mathrm{D} 727$.

https://doi.org/10.1063/1.4867596

Copyright 2014 American Institute of Physics. This article may be downloaded for personal use only. Any other use requires prior permission of the author and the American Institute of Physics. The following article appeared in Journal of Applied Physics, 115(17), 17D727 and may be found at https://doi.org10.1063/1.4867596 


\section{Authors}

K. Rainey, J. Chess, J. Eixenberger, D. A. Tenne, C. B. Hanna, and A. Punnoose

This article is available at ScholarWorks: https://scholarworks.boisestate.edu/physics_facpubs/148 


\title{
Defect induced ferromagnetism in undoped $\mathrm{ZnO}$ nanoparticles
}

\author{
K. Rainey, J. Chess, J. Eixenberger, D. A. Tenne, C. B. Hanna, and A. Punnoose ${ }^{\text {a) }}$ \\ Department of Physics, Boise State University, Boise, Idaho 83725, USA
}

(Presented 7 November 2013; received 23 September 2013; accepted 29 November 2013; published online 26 March 2014)

\begin{abstract}
Undoped $\mathrm{ZnO}$ nanoparticles (NPs) with size $\sim 12 \mathrm{~nm}$ were produced using forced hydrolysis methods using diethylene glycol (DEG) [called $\mathrm{ZnO}-\mathrm{I}$ ] or denatured ethanol [called $\mathrm{ZnO}-\mathrm{II}$ ] as the reaction solvent; both using $\mathrm{Zn}$ acetate dehydrate as precursor. Both samples showed weak ferromagnetic behavior at $300 \mathrm{~K}$ with saturation magnetization $\mathrm{M}_{\mathrm{s}}=0.077 \pm 0.002 \mathrm{memu} / \mathrm{g}$ and $0.088 \pm 0.013 \mathrm{memu} / \mathrm{g}$ for $\mathrm{ZnO}-\mathrm{I}$ and $\mathrm{ZnO}-\mathrm{II}$ samples, respectively. Fourier transform infrared (FTIR) spectra showed that ZnO-I nanocrystals had DEG fragments linked to their surface. Photoluminescence (PL) data showed a broad emission near $500 \mathrm{~nm}$ for $\mathrm{ZnO}-\mathrm{II}$ which is absent in the $\mathrm{ZnO}-\mathrm{I}$ samples, presumably due to the blocking of surface traps by the capping molecules. Intentional oxygen vacancies created in the $\mathrm{ZnO}-\mathrm{I}$ NPs by annealing at $450^{\circ} \mathrm{C}$ in flowing Ar gas gradually increased $\mathrm{M}_{\mathrm{s}}$ up to $90 \mathrm{~min}$ and $\mathrm{x}$-ray photoelectron spectra (XPS) suggested that oxygen vacancies may have a key role in the observed changes in $\mathrm{M}_{\mathrm{s}}$. Finally, PL spectra of $\mathrm{ZnO}$ showed the appearance of a blue/violet emission, attributed to $\mathrm{Zn}$ interstitials, whose intensity changes with annealing time, similar to the trend seen for $\mathrm{M}_{\mathrm{s}}$. The observed variation in the magnetization of $\mathrm{ZnO} \mathrm{NP}$ with increasing $\mathrm{Ar}$ annealing time seems to depend on the changes in the number of $\mathrm{Zn}$ interstitials and oxygen vacancies. @ 2014 AIP Publishing LLC. [http://dx.doi.org/10.1063/1.4867596]
\end{abstract}

Zinc Oxide ( $\mathrm{ZnO})$ nanoparticles (NPs) have been a large focus in materials research. Because of their small size, NPs of many oxide materials such as $\mathrm{ZnO}$ display novel properties, including room temperature ferromagnetism (RTFM). ${ }^{1}$ Several types of lattice defects, including oxygen vacancies, metal interstitials, and metal vacancies, have been proposed as the source of the RTFM in undoped oxide nanoparticles. $^{2,3}$ However, clear evidence on the role of surface defects on this unusual ferromagnetism in undoped oxide NP is lacking. To investigate the role and type of defects contributing to the RTFM of $\mathrm{ZnO}$ NPs, their magnetic behavior is investigated as a function of defects introduced intentionally by annealing in $\mathrm{Ar}$ atmosphere at $450^{\circ} \mathrm{C}$.

All undoped $\mathrm{ZnO}$ NPs used in this study were produced using one of two forced hydrolysis methods, both using $\mathrm{Zn}$ acetate dehydrate as precursor, with DEG (referred to as $\mathrm{ZnO}-\mathrm{I})$ or denatured ethanol (ZnO-II) as the reaction solvent. Details of their synthesis and characterization are discussed in Ref. 4.

As prepared samples were annealed in the $200-750^{\circ} \mathrm{C}$ range in Ar atmosphere (flow rate $20 \mathrm{ml} / \mathrm{min}$ ) using a Netzsch Simultaneous Thermal Analysis (STA) 449 F1, capable of monitoring both mass and energy changes. This STA unit was used in combination with a quadrupole mass spectrometry (QMS) evolved gas analysis system to monitor elemental and molecular burn-off. It was determined that $450{ }^{\circ} \mathrm{C}$ was the optimal temperature to remove organic precursors while causing the least grain growth. Samples were annealed at $450^{\circ} \mathrm{C}$ for varying amounts of time $(30,45,60$, 75,90 , and $120 \mathrm{~min}$ ). The as-prepared and annealed samples

\footnotetext{
a) Author to whom correspondence should be addressed. Electronic mail: apunnoos@boisestate.edu.
}

were analyzed using X-ray diffraction (XRD), XPS, vibrating sample magnetometry (VSM), FTIR, and low temperature ( $\sim 10 \mathrm{~K})$ photoluminescence (PL) and Raman spectra (with a $325 \mathrm{~nm}$ UV excitation) following procedures described elsewhere. ${ }^{4}$ These studies confirmed the absence of contamination in samples.

XRD patterns confirm the samples to be single phase wurtzite $\mathrm{ZnO}$ with no detectable secondary phases. Lattice parameters and crystallite size determined using Rietveld refinement methods revealed an average crystallite size of $12.3 \pm 0.35 \mathrm{~nm}$ for both $\mathrm{ZnO}-\mathrm{I}$ and $\mathrm{ZnO}-\mathrm{II}$. Lattice parameters were around $\mathrm{a}=3.25 \pm 0.0003 \AA$ and $\mathrm{c}=5.21 \pm 0.003 \AA$ for the as-prepared and annealed samples. Samples displayed growth up to $\sim 29 \mathrm{~nm}$ when the NPs were annealed at $450{ }^{\circ} \mathrm{C}$, attributed to the expected sintering process.

The FTIR spectra of ZnO-I and ZnO-II are shown in Figs. 1(a) and 1(b). The data showed the major characteristic $\mathrm{Zn}-\mathrm{O}$ vibrations ${ }^{5}$ at $478 \mathrm{~cm}^{-1}$ in $\mathrm{ZnO}-\mathrm{I}$ and $444 \mathrm{~cm}^{-1}$ in ZnO-II. The broad absorptions around $3410-3420 \mathrm{~cm}^{-1}$ due to hydroxyl groups are relatively stronger in $\mathrm{ZnO}$-I. Presence of fragments of DEG is observed in ZnO-I NP. No such surfactant layer is present on ZnO-II NP. The ZnO-I sample exhibits two strong bands, commonly associated with the carboxylate functional group, at $1412 \mathrm{~cm}^{-1}\left[\nu_{\mathrm{s}}\left(\mathrm{COO}^{-}\right)\right]$and $1595\left[\nu_{\text {as }}\left(\mathrm{COO}^{-}\right)\right] \cdot{ }^{6,7}$ Additionally, weaker bands consistent with $\tau\left(\mathrm{CH}_{2}\right)$ and $\nu(\mathrm{C}-\mathrm{OH})$ at 907 and $1067 \mathrm{~cm}^{-1}$ are also observed. ${ }^{6-8} \mathrm{ZnO}$-II also showed many of these bands due to surface adsorbed groups resulting from the acetate groups, but with somewhat lower intensity and at slightly different frequencies, presumably due to the absence of a surfactant like DEG in this sample.

The PL spectra of the samples recorded at $10 \mathrm{~K}$ using a $325 \mathrm{~nm} \mathrm{He}: \mathrm{Cd}$ laser are shown in Figures 1(c) and 1(d). 


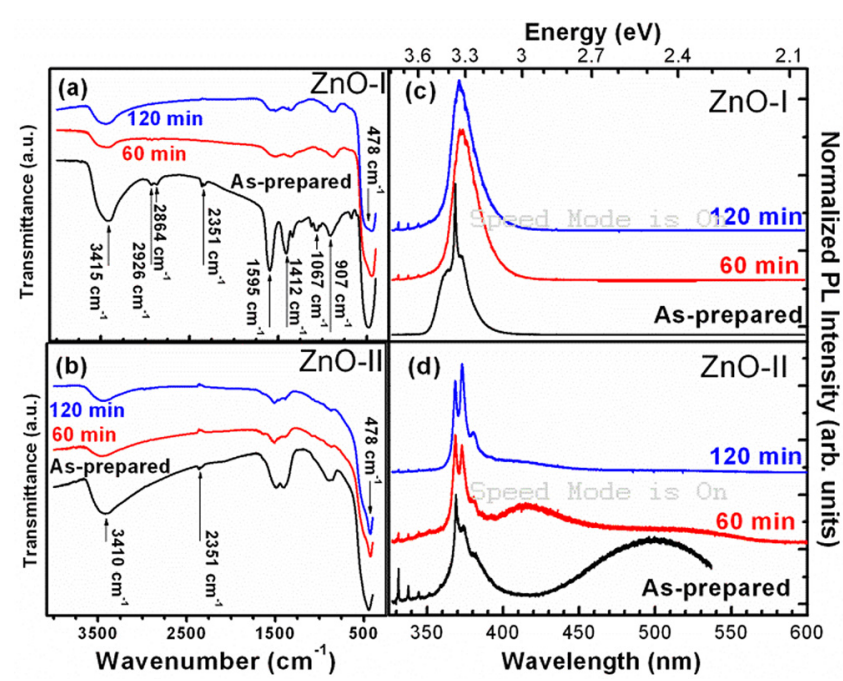

FIG. 1. FTIR and PL spectra of annealed (60 and $120 \mathrm{~min})$ and as-prepared $\mathrm{ZnO}-\mathrm{I}[(\mathrm{a}),(\mathrm{c})]$ and $\mathrm{ZnO}-\mathrm{II}[(\mathrm{b}),(\mathrm{d})]$.

Higher order Raman peaks appear in the spectra caused by resonance Raman scattering due to the band gap approaching the excitation laser line. The UV emission band at $\sim 3.37 \mathrm{eV}$ can be explained by a near band-edge transition of wide band gap $\mathrm{ZnO}$ NPs, the free exciton recombination through an exciton-exciton collision process. It has been theoretically proposed that the position of the $\mathrm{Zn}$ interstitials $\left(\mathrm{Zn}_{\mathrm{i}}\right)$ in the $\mathrm{ZnO}$ band structure is about $0.22 \mathrm{eV}$ below the conduction band. ${ }^{9}$ So a radiative transition from the acceptor states due to such $\mathrm{Zn}_{\mathrm{i}}$ to the valence band will result in a blue/violet emission in the 400-450 $\mathrm{nm}$ range. Energy levels corresponding to oxygen interstitial $\left(\mathrm{O}_{\mathrm{i}}\right)$ and oxygen vacancy $\left(\mathrm{V}_{\mathrm{o}}\right)$ are located at $2.28 \mathrm{eV}$ and 1.85 below the conduction band. Orange-red emissions centered at $\sim 600-760 \mathrm{~nm}$ are generally attributed to deep level defects such as vacancies and interstitials of oxygen. These orange-red emissions are experimentally observed in oxygen-rich sample suggesting that $\mathrm{O}_{\mathrm{i}}$ may be the dominant player. ${ }^{10}$ Green emission is most likely due to oxygen vacancies. ${ }^{10}$ In oxygen deficient samples, both oxygen vacancies and zinc interstitials might exist as potential defects. The oxygen vacancies can form two types of defect states: a shallow donor level and a deep donor level. While the shallow donor level is very close to the conduction band, the deep donor level is $\sim 0.7-0.8 \mathrm{eV}$ below the conduction band. ${ }^{11}$ The energy difference between the deep donor level and the top of the valence band is about $2.43-2.53 \mathrm{eV}$, and this is consistent with the green emission energy. Zinc interstitials also can be formed in zinc-rich samples, which can act as electron donors. Both oxygen vacancies and zinc interstitials have low formation energies, but oxygen vacancies are expected to be the dominant defects in nanoparticles due to their large surface to volume. According to the existing models, ${ }^{12}$ surface sites are proposed to be responsible for all non-excitonic relaxation processes in NPs. There are two potential relaxation processes proposed in these models. In one case, a hole from the valence band can be trapped by surface $\mathrm{O}^{2-}$ sites, thus producing $\mathrm{O}^{-}$sites. A green emission can occur if the hole tunnels to the singly ionized oxygen vacancy in the neighborhood.
Another possibility is that an electron from the conduction band gets trapped on a surface $\mathrm{O}^{-}$to become $\mathrm{O}^{2-}$. A green emission can occur if this $\mathrm{O}^{2-}$ traps a hole.

Thus, the as-prepared $\mathrm{ZnO}-\mathrm{II} \mathrm{NP}$ with large green emission might have large number of oxygen vacancies. Annealing it in Argon atmosphere at $450^{\circ} \mathrm{C}$ for $1 \mathrm{~h}$ produces a new blue/violet emission centered at $416 \mathrm{~nm}$. It seems that the blue/violet emission and the exciton emission increased in intensity at the expense of green emission (Figures 1(c) and 1(d)). It appears that the annealing process in Ar atmosphere produced a $\mathrm{Zn}$-rich sample with large number of $\mathrm{Zn}_{\mathrm{i}}$ to generate the blue/violet emission. Increased number of carriers or larger crystallite size due to sintering might have enhanced exciton emission also. Further increase in the annealing time to $2 \mathrm{~h}$ reduced the green emission while the intensity of the exciton emission increased significantly. The blue/violet emission intensity also somewhat decreased. Interestingly, the ZnO-I NPs prepared using DEG did not show any of the visible emissions and no significant change in the intensity of the exciton emission was observed. The FTIR data clearly showed that DEG molecules are present on the NP surface. Note that $\mathrm{O}^{2-}$ surface trap in $\mathrm{ZnO}$ nanocrystals are actually OH- which is also seen in the FTIR data. Capping ZnO-I nanocrystals with organic molecules such as DEG might have removed the surface hole traps. Absence of both green and blue/violet emissions in this samples indicates that both these emissions are related to surface structure/defects.

Magnetization (M) of the NPs as a function of applied magnetic field $(\mathrm{H})$ was measured over the range of $\pm 1 \mathrm{~T}$. A diamagnetic susceptibility, $\chi=-7.438 \times 10^{-8}$ emu/Oe, from the straw was subtracted from all data. All samples showed a weak ferromagnetic component with open hysteresis loops at room temperature, superimposed on an overall paramagnetic signal. The saturation magnetization $\left(\mathrm{M}_{\mathrm{s}}\right)$ of the as-prepared $\mathrm{ZnO}-\mathrm{II}$ had a slightly higher $\mathrm{M}_{\mathrm{s}}$ of $0.088 \pm 0.013 \mathrm{memu} / \mathrm{g}$ compared to $0.077 \pm 0.002 \mathrm{memu} / \mathrm{g}$. Interestingly, the $\mathrm{M}_{\mathrm{s}}$ values follow a clear trend in both samples as shown in Figure 2(a). $M_{s}$ gradually increases with annealing time, reaching a maximum after $75 \mathrm{~min}$ of annealing, followed by a decrease for $120 \mathrm{~min}$.

The binding energy (BE) of $\mathrm{Zn} 2 p_{3 / 2}$ peak of the as-prepared and annealed samples is centered around $1021.2-1021.5 \mathrm{eV}$, with a spin-orbit splitting $(\Delta S)$ of $23.1 \mathrm{eV}$, as expected for $\mathrm{Zn}^{2+}$ ions. The $\mathrm{O} 1 \mathrm{~s}$ spectra showed broad asymmetric features, which were fitted by two components, indicating the presence of two different sources of oxygen ions with different chemical environments in both as-prepared as well as annealed $\mathrm{ZnO}$ samples. The relatively stronger component on the lower binding energy side, in the range of $530.2-529.9 \mathrm{eV}$, can be attributed to $\mathrm{O}^{2-}$ ions on the wurtzite structure surrounded by $\mathrm{Zn}^{2+}$ atoms in tetrahedral sites, located mainly in the core region of the NPs. As annealing time increased from 0 to $120 \mathrm{~min}$, the BE showed a systematic increase from 529.69 to $529.79 \mathrm{eV}$. This might be the result of increasing formation of oxygen vacancies or $\mathrm{Zn}$ interstitials. The second $\mathrm{O} 1 \mathrm{~s}$ peak was observed at $531.1-531.6 \mathrm{eV}$ is ascribed to oxygen ions on the surface region of the NP, probably related to $-\mathrm{OH}$ groups 


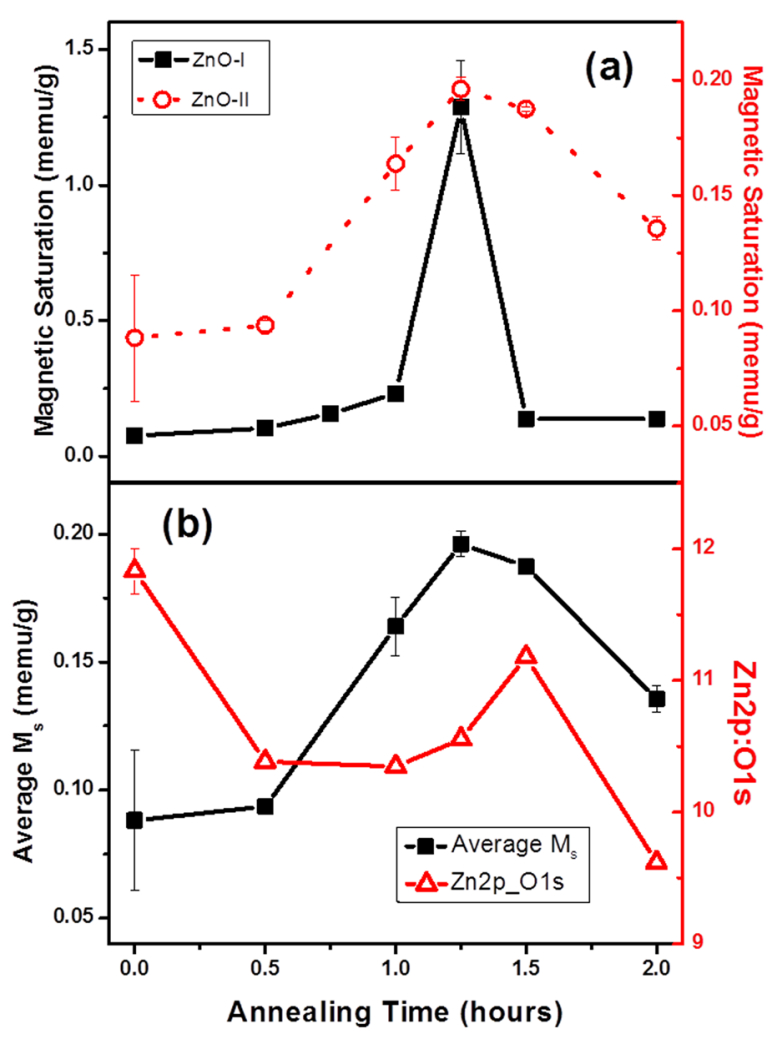

FIG. 2. (a) Trend in $\mathrm{M}_{\mathrm{s}}$ of annealed ZnO-I (black squares; left $\mathrm{y}$-axis) and annealed $\mathrm{ZnO}-\mathrm{II}$ (red circles; right y-axis) as a function of annealing time. (b) Ratio of $\mathrm{Zn} 2 \mathrm{p}$ area to $\mathrm{O} 1 \mathrm{~s}$ and $\mathrm{M}_{\mathrm{s}}$ trend of $\mathrm{ZnO}-\mathrm{II}$ with annealing time.

chemisorbed on the surface, as observed in FTIR data also, indicating the presence of loosely bound oxygen near the surface region of $\mathrm{ZnO}$ nanoparticles. Changes in this component may be related to changes in the concentration of oxygen vacancies and/or oxygen interstitials on the surface of $\mathrm{ZnO}$ NPs. As annealing time increased from 0 to $120 \mathrm{~min}$, area of the larger peak $(\sim 1021 \mathrm{eV})$ increased from $62.2 \%$ to $72 \%$ while that of the smaller peak $(\sim 1044 \mathrm{eV})$ decreased from $37.8 \%$ to $28 \%$. Furthermore, with increasing annealing time, the smaller peak showed a systematic shift from 531.13 to $531.45 \mathrm{eV}$. These gradual changes in intensity and peak position suggest that annealing in Ar leads to more oxygen vacancies in the surface region of the NPs, while at the same time, in the core of the nanocrystals, this process might have filled any oxygen vacancies and possibly introduced some oxygen interstitials too. Figure 2(b) shows a plot of the relative XPS intensity of $\mathrm{Zn} 2 \mathrm{p}$ and the main $\mathrm{O} 1 \mathrm{~s}$ peaks obtained from $\mathrm{ZnO}$-II NPs plotted as a function of annealing time. Also plotted in this figure are $\mathrm{M}_{\mathrm{s}}$ values measured at $300 \mathrm{~K}$. The observed similarity between the behavior of $\mathrm{M}_{\mathrm{s}}$ and the relative oxygen stoichiometry indicates that oxygen vacancies might be playing a role in the observed RTFM. In the beginning, increasing temperature breaks down surface attached acetate groups and hydroxyl groups, making more oxygen ions available to the crystals and this might have caused the observed difference between $\mathrm{M}_{\mathrm{s}}$ and $\mathrm{Zn}: \mathrm{O}$ ratio initially. FTIR data indicate that this process continues throughout the duration of annealing, although the rate of dissociation of these groups decreases significantly with increasing time. While this process adds oxygen ions, another simultaneous process taking place during this Ar annealing is the formation of oxygen vacancies and $\mathrm{Zn}_{\mathrm{i}}$, as evidenced from PL data. These competing processes may be responsible for the maximum in $\mathrm{Zn}: \mathrm{O}$ ratio and $\mathrm{M}_{\mathrm{s}}$, shown in Fig. 2(b).

What is responsible for the observed RTFM in undoped $\mathrm{ZnO}$ ? Weak RTFM is observed in the as-prepared $\mathrm{ZnO}$ NPs. As shown in Fig. 2, $\mathrm{M}_{\mathrm{s}}$ increased significantly after $1 \mathrm{~h}$ of annealing in Ar and then it decreases when annealed for $2 \mathrm{~h}$. The same trend is observed in both $\mathrm{ZnO}-\mathrm{I}$ and $\mathrm{ZnO}-\mathrm{II}$ samples. Role of oxygen vacancies in the magnetic behavior of $\mathrm{ZnO}$ NPs is indicated from the XPS data (Figure 2(b)). Absence of capping molecules in $\mathrm{ZnO}-\mathrm{II}$ allows it to emit green presumably due to the presence of large number of oxygen vacancies. However, its intensity decreases with increasing $\mathrm{Ar}$ annealing time and a blue/violet emission starts appearing, suggesting significant changes in the defect composition and the formation of more $\mathrm{Zn}_{\mathrm{i}}$. The observed changes in the intensity of the blue/violet emission correlate with the observed variation of $M_{s}$ suggesting that $Z_{i}$ may also be a key player in the observed magnetic properties of $\mathrm{ZnO}$ NPs. It seems that the blue emission grows at the expense of green emission, indicating that the processes that create $\mathrm{Zn}_{\mathrm{i}}$ and $\mathrm{V}_{\mathrm{o}}$ may be related.

This work was supported in part by the National Science Foundation grants EAGER DMR-1137419, CBET 1134468, DMR 1006136, and DMR 1006136. We thank D. A. Hillsberry and Dr. K. M. Reddy for help with this article.

${ }^{1}$ M. A. Garcia et al., Nano Lett. 7, 1489 (2007).

${ }^{2}$ A. Sundaresan et al., Phys. Rev. B 74, 161306(R) (2006).

${ }^{3}$ N. S. Norberg and D. R. Gamelin, J. Phys. Chem. B 109, 20810-20816 (2005).

${ }^{4}$ L. M. Johnson et al., Phys. Rev. B 82, 054419 (2010).

${ }^{5}$ I. A. Farbun et al. Russ. J. Appl. Chem. 80, 1798-1803 (2007).

${ }^{6}$ S.-W. Bian, I. A. Mudunkotuwa, T. Rupasinghe, and V. H. Grassian, Langmuir 27, 6059-6068 (2011).

${ }^{7}$ J. J. Max and C. Chapados, J. Phys. Chem. A 108, 3324-3337 (2004).

${ }^{8}$ I. A. Mudunkotuwa et al., Langmuir 28, 396-403 (2012).

${ }^{9}$ V. Kumar et al., Mater. Lett. 101, 57 (2013).

${ }^{10}$ L. Wu et al., Opt. Mater. 28, 418 (2006).

${ }^{11}$ Q. P. Wang et al., Opt. Mater. 26, 23 (2004).

${ }^{12}$ A. v. Dijken et al., J. Phys. Chem. B 104, 1715 (2000). 